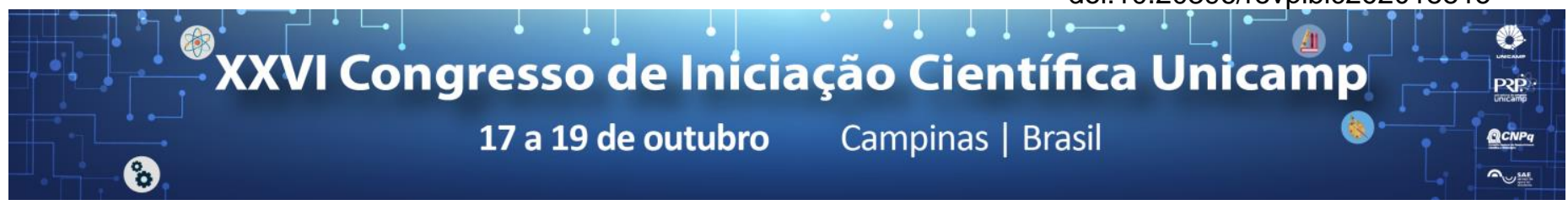

\title{
Estudo de proteção em sistema elétrico de potência
}

\section{Leonardo Felipe Toso*, Professora Dra. Maria Cristina Dias Tavares,Dr. Ozenir Farah da Rocha Dias.}

\section{Resumo}

A pesquisa proposta no projeto de Iniciação Científica, realizada no Laboratório de Estudos de Transitórios Eletromagnéticos e de Proteção em Sistema de Potência (LTRANSP) teve o enfoque no estudo do comportamento da proteção diferencial de transformador utilizada em um sistema elétrico de potência. A proposta foi reproduzir os problemas encontrados em campo, tanto de saturação dos equipamentos de medição, quanto de manobras e defeitos que acarretam na operação indevida dos relés de proteção.

\section{Palavras-chave:}

Proteção diferencial, sistema elétrico, relé de proteção.

\section{Introdução}

O objetivo do projeto foi realizar uma análise de um sistema elétrico real reduzido, modelando os equipamentos de potência e os equipamentos de medição. O sistema elétrico foi simulado a partir de dados reais obtidos de concessionárias, sendo então submetido a diversas situações análogas às que ocorrem na prática. As simulações foram realizadas no simulador digital em tempo real, RTDS, em conjunto com os relés comerciais.

Para que esta análise fosse realizada com sucesso foi necessário que os estudos fossem divididos em três etapas, consistindo de uma análise bibliográfica dos trabalhos já existentes na área, após isto foi realizado, uma familiarização com os equipamentos existentes no laboratório e por fim realizou-se a aplicação dos conhecimentos no estudo de um sistema elétrico de potência real.

\section{Resultados e Discussão}

Os resultados do projeto se pautaram na análise das simulações de um sistema elétrico real no simulador digital em tempo real, RTDS, para isso após o período de familiarização com os equipamentos do laboratório, utilizando o relé 787-SEL foi possível parametrizar este equipamento de proteção de forma que o mesmo pudesse atuar em situações que são consideradas anormais no sistema.

Após a parametrização do relé utilizado, elaborou-se o diagrama de um sistema elétrico no software RSCAD a partir dos dados obtidos das concessionárias, para que então fosse possível realizar simulações em malha fechada, caracterizada pela comunicação do relé com o RTDS e então analisar a atuação do relé neste sistema.

Para determinar se o relé foi parametrizado correntemente e se a sua atuação no sistema foi satisfatória foram aplicadas faltas no sistema, tanto de natureza monofásica quanto bifásica para que então pudéssemos analisar a atuação do relé perante condições de anormalidade do sistema.

\section{Conclusões}

Após realizar as simulações no RTDS foi possível concluir que o relé diferencial de transformador utilizado atuou corretamente as condições anormais do sistema. Nestas condições o relé não indicou que houve falta interna.

Desta forma conclui-se que o trabalho realizado foi satisfatório de modo que conseguimos elaborar a análise da proteção diferencial de transformador em um sistema elétrico real como foi proposto para o projeto de iniciação cientifica.

\section{Agradecimentos}

Acredito que, ao final desta iniciação científica, ter participado do projeto juntamente com a Profa. Dra. Maria Cristina Dias Tavares e os mestrandos e doutorandos do laboratório contribuiu muito para meu crescimento não apenas acadêmico, mas também para meu crescimento como futuro pesquisador. Foi muito prazeroso poder estar no laboratório ajudando de todas as formas possíveis, estudar os conteúdos referentes ao que estávamos trabalhando e ter tido um contato maior com o dia a dia de um pesquisador.

Agradeço grandemente a existência do programa PIBIC, ao CNPq e a Profa. Dra. Maria Cristina Dias Tavares por terem me ajudado a conhecer um pouco mais do ramo de pesquisas existentes na universidade. 